DOI: http://dx.doi.org/10.5007/1980-3532.2015n13p75

\title{
Ciência Política no Ensino médio: Reconhecimento, diálogos e itinerários da institucionalização de uma área
}

\author{
Political Science in high school: \\ Recognition, dialogues and itineraries of the institutionalization \\ of an área
}

Jesus Marmanillo Pereira Doutorando em Sociologia pela Universidade Federal da Paraíba Professor Assistente da Universidade Federal do Maranhão jesusmarmanillo@hotmail.com

\begin{abstract}
Resumo: O presente artigo visa delinear uma etapa da institucionalização da Ciência Política, que corresponde a determinados debates e ações orientados para a inserção dessa área no ensino médio. A partir daí buscamos elencar quais as principais influências, argumentos e contextos que caracterizam um campo heterônomo - ora de disputa disciplinar, ora pelo discurso da interdisciplinaridade. Por fim, analisamos os conteúdos de dessa disciplina trabalhados em um livro didático de Sociologia, verificando que essa mesma lógica heterônoma também é vinculada a outros aspectos, como a pluralidade de métodos da Ciência Política, em outros níveis de ensino e os processos mais amplos de formação de licenciados e de institucionalização dessa área.
\end{abstract}

Palavras- chave: Institucionalização; Sociologia; Ciência Política; Ensino Médio; livro didático

\begin{abstract}
This article aims to outline a stage of institutionalization of political science, which corresponds to certain discussions and actions oriented to the inclusion of this area in high school. From there we seek to list what are the main influences, arguments and contexts featuring a heteronomous field - now of disciplinary dispute, now the interdisciplinary discourse. Finally, we analyze the content of this course worked on a textbook Sociology, noting that the same heteronomous logic is also linked to other aspects such as the plurality of political science methods in other levels of education and the broader processes training of graduates and institutionalization
\end{abstract}

Key words: Institutionalization; Sociology; Political science; High school; textbook

Originais recebidos em: 08/03/2016

Aceito para publicação em: 13/05/2016

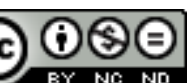

EY NC ND Este trabalho está licenciado sob uma Licença Creative Commons Atribuição-Uso NãoComercial-Vedada a criação de obras derivadas 3.0 Unported License. 


\section{Introdução}

Considerando o pressuposto de Bourdieu (2004) quando defende que a produção científica deve de antepor aos automatismos do pensamento e necessita de um conjunto de princípios de visão e de divisão vinculadas à forma como o pesquisador percebe a construção social dos problemas sociológicos, o presente artigo visa problematizar o processo de institucionalização da Ciência Política no âmbito da prática educativa.

Assim, traremos aqui uma breve reflexão sobre os caminhos dessa disciplinaem relação ao Ensino Médio, atentando para os diálogos com outras áreas, os principais fatos e a situação atuais dessa disciplina, na qual cremos que, hipoteticamente, apresenta-se em um processo de busca por legitimidade que pode ser visualizado por meio de conjunto de ações, posições, interesses que nem sempre estão atrelados as necessidades e dinâmicas internas no âmbito da produção de conhecimento emCiência Política. Dessa forma, veremos que o caminho de institucionalização dessa área no ensino médio é permeado por ações e marcas de especialistas diversos como advogados, sociólogos e outros que atuam não apenas na esfera da educação, mas também da política, associações de professores e outras.

Tal exercício reflexivo foi orientado pelas noções de processo (ELIAS, 2006) e heteronomia (BOURDIEU, 1990), a primeira significando transformações contínuas mobilizadas por (com)figurações formadas por seres humanos cujos aspectos seguem distintas direções, sendo geralmente uma de ascensão e outra de declínio. Já a segunda noção diz respeito à capacidade de um determinado campo ter o próprio funcionamento influenciado por lógicas externas orientadas por outros interesses ${ }^{1}$. Nesse sentido, verificaremos que em muitas situações o processo de fomento e defesa da ciência Política no ensino médio, foi composto por aspectos de heteronomia, ou seja, sem capacidade de impor uma hierarquia e lógica própria- relacionada ao acumulo da própria história, interesses e funções da Ciência Política.

\footnotetext{
${ }^{1}$ Um exemplo de estudo de estruturação do campo de ciências sociais que expõem modelos heterônomos e com mais autonomia, pode ser visto no estudo "Condicionantes do Desenvolvimento das Ciências Sociais no Brasil: 1930-1964", de Sergio Miceli. Como exemplos, o autor explica o campo das ciências sociais no Rio de Janeiro e São Paulo, apontando que no primeiro caso as orientações da política, confessionais e locais eram determinantes no funcionamento da universidade enquanto em São Paulo, os pesquisadores conseguiram arquitetar uma lógica de funcionamento cientifico e profissionalização cada vez mais afastado e menos influenciado dos interesses das demandas sociais empresariais. Tais exemplos apontam caminhos de profissionalização e concepções que sinalizam respectivamente casos de heteronímia e autonomia.
} 
Guiados para problematizar e verificar essa ideia, buscaremos mapear esse campo de lutas, ou seja, pensar as relações entre disciplinas (Sociologia, Filosofia, Antropologia e Ciência Política) como um tipo de campo no qual os conhecimentos específicos se confrontam para conservar ou transformar as relações de força no decorrer do processo de discussão e implementação de temas políticos nos conteúdo do ensino médio- via estratégica de legitimação que pode ser utilizada para a institucionalização da Ciência Política. Empiricamente, utilizo fontes documentais tais como: reportagens e dados oficiais (os Parâmetros Curriculares Nacionais [PCN]), a Resolução CNE/CEB n 3/98, a Lei Nº. 394 de 20 de dezembro de 1996, o PL $7746 / 2010$, e os pareceres CEE No 343/2007 e No: 38/2006). Tais dados, além de nos trazerem importantes informações históricas, foram tratados como formas de ações de especialistas, intelectuais e professores, ou seja, como instrumentos de percepção e de expressão do mundo social. Seguindo uma influência da orientação bourdiana e elisiana na análise dessas fontes, o artigo trará uma breve história social a respeito das possíveis formas de introdução da Ciência Política no Ensino Médio e as relações estabelecidas entre Ciência Política, Direito, Filosofia e Sociologia.

\section{Ciência Política no Ensino Médio: uma breve história de lutas}

Ao analisar as relações (de coalização e conflito) entre várias classes sociais) no livro 18 Brumário de Louis Bonaparte, Marx(1982), observa a heterogeneidade de grupos e as formas como os conflitos se materializam em um conjunto de ações políticas em torno da produção de documentos e leis. Para esse autor cada parágrafo da constituição francesa continha em si sua própria antítese, sua própria câmara alta e câmara baixa, ou seja, cada parágrafo da constituição sinalizada os interesses políticos e econômicos de determinadas classes sociais. Nessa lógica, é possível pensar que as relações sociais se reproduzem e possuem reflexos não apenas no cotidiano e experiências ligadas diretamente aos grupos, mas também se materializam em produtos coletivos ${ }^{2}$ como $^{2}$ documentos, monumentos e outros.

Nesse sentido, a grade do Ensino Médio também pode ser compreendida como um produto coletivo- fruto de um processo de disputas, de negociações e de trabalho social.Para desenvolver melhor tal argumento cremos ser necessário algumas operações

\footnotetext{
2 Como por exemplo: Atas de reunião, leis, relatórios, estátuas.
} 
fundamentais como: a) Descrever sobre a forma de inserção da Ciência Política no Ensino Médio, b) Detalhar quais são os conteúdos e áreas relacionadas a tal processo de inserção. Para tanto,valemo-nos da análise dos Parâmetros Curriculares nacionais (PCN), dos conteúdos de Ciência Política contidos no livro Sociologia para o Ensino Médio de Nelson Dacio Tomazi e em outros documentos que demonstrem o processo de institucionalização dessa área nas escolas, tais como:projetos de lei, pareceres e textos de especialistas que defendiam a implementação.

Ao buscar uma trajetória da Ciência Política no Ensino Médio é possível notar que tal disciplina sempre esteve mencionada de forma indireta e/ou associada a outras disciplinas como Sociologia e Filosofia. Isso a começar pela Lei N9.394, de 20 de dezembro de 1996, que estabelecia asdiretrizes e bases da educação brasileira. Segundo o Art. 36 desse texto ${ }^{3}$, os alunos deveriam finalizar o Ensino Médio com o domínio de conteúdos da Filosofia e da Sociologia necessários ao exercício da cidadania. Como é possível observar, a referida lei, apesar de trazer um conceito bastante característico da Ciência Política, o de cidadania, o atrelava aos conteúdos das áreas próximas- Filosofia e Sociologia.

Observando as Diretrizes Curriculares Nacionais da Educação Básica (DCNEB), notamos que, após dois anos, o artigo 10 da Resolução CNE/CEB nº 3/98 explica:

$\S 2^{\circ}$ As propostas pedagógicas das escolas deverão assegurar tratamento interdisciplinar e contextualizado para: a) Educação Física e Arte como componentes curriculares obrigatórios;b) Conhecimentos de Filosofia e Sociologia necessários ao exercício da cidadania. (DCNEB, 2001, 106-107) ${ }^{4}$

Dessa forma, Sociologia e Filosofia sequer poderiam ser compreendidas institucionalmente como disciplinas. Cabe ressaltar que entre os anos de 1997 e 2001 houve uma proposta de inclusão da Sociologia como disciplina obrigatóriano Ensino Médio, aprovada na Câmara dos Deputados e no Senado Federal, porém vetada pelo então presidente Fernando Henrique Cardoso em 8 de outubro de 20015. Tais

\footnotetext{
${ }^{3}$ Disponível em: http://portal.mec.gov.br/par/323-secretarias-112877938/orgaos-vinculados82187207/12768-filosofia-e-sociologia-no-ensino-medio-sp-1870990710. Acesso em 20 de março de 2016.

${ }^{4}$ Documento disponível nos sites: http://www.dominiopublico.gov.br/download/texto/me002630.pdf http://portal.mec.gov.br/setec/arquivos/pdf/rceb04_06.pdf. Acesso em 25 de março de 2016.

5 Disponível em: http://politica.estadao.com.br/noticias/geral,fhc-veta-filosofia-e-sociologia-no-ensinomedio,20011009p33663. Acessado em 15 de dezembro de 2015.
}

Revista Em Debate (UFSC), Florianópolis, volume 13, p. 75-95, 2015. ISSNe 1980-3532 
contextossinalizaram um distanciamento condicionado cada vez maior para a inclusão das noções da Ciência Política no Ensino Médio. Por conta de um conjunto de esforços relacionados à atuação da Sociedade Brasileira de Sociologia, educadores e sindicatos estaduais que produziram pareceres ${ }^{6}$ explicativos sobre a necessidade da disciplina, ocorreu um processo de diálogo e negociação junto ao MEC. Um exemplo disso foi o texto intitulado "Sociologia e Filosofia nas escolas e a crise educacional brasileira", escrito por Cesar Callegari ${ }^{7}$.Enfim, desse contexto de trabalho coletivo resultou que no ano de 2008 o Congresso Nacional aprovou o projeto de lei $\mathrm{n}^{\circ} 1.641 / 2003$ que foi sancionado pelo presidente em exercício, José de Alencar ${ }^{8}$, como lei nº11.684/2008 que alterava a LDB, tornando obrigatórias as disciplinas Sociologia e Filosofia nas três séries do Ensino Médio.

Pode-se dizer que institucionalmente isso sinalizou uma possibilidade de abertura concreta para a introdução da Ciência Política no Ensino Médio. Nesse mesmo caminho, vale ressaltar que no ano de 2000 houve a publicação do Parâmetro Curricular Nacional (PCN), que previa a necessidade de trabalhar com conceitos de Ciência Política, especificamente em uma seção chamada "Conhecimentos de Sociologia, Antropologia e Política", integrada ao que o MEC classificou como "Ciências Humanas e suas Tecnologias". Esse documento pode ser analisado sobre as dimensões de um conjunto de conteúdos e habilidades desejadas para serem desenvolvidas nos alunos.

No que concerne a Ciência Política, esse documento defende e explica a necessidade da ampliação da noção de política "enquanto um processo de tomada de decisões sobre os problemas sociais que afetam a coletividade" (p.41) e como elemento presente, também, nas relações sociais cotidianas e nos vários grupos sociais como a escola, a família, a fábrica e outros presentes na vida dos alunos. O texto valoriza, assim, a dimensão social da política, ou seja, das relações sociais, dos movimentos sociais, instituições e outros fenômenos sociológicos que são também permeados por dinâmicas políticas próprias. Tal postura não pode ser desvinculada de uma forma de

\footnotetext{
${ }^{6}$ Um exemplo disso foi à produção dos documentos: PARECER CEE $N^{\circ}$ 343/2007 e PARECER CNE/CEB N $: 38 / 2006$

${ }^{7}$ Era membro do Conselho Nacional de Educação, Secretário Municipal de Educação de Taboão da Serra, Presidente do Instituto Brasileiro de Sociologia Aplicada - IBSA, Presidente do Conselho de Acompanhamento e Controle Social do FUNDEB no âmbito da União e Membro do Comitê Nacional de Políticas de Educação Básica.

8 Disponível em: http://g1.globo.com/Noticias/Vestibular/0,,MUL586712-5604,00SANCIONADA+LEI+QUE+TORNA+FILOSOFIA+E+SOCIOLOGIA+OBRIGATORIAS+NO+ENSIN O+MEDI.html. Acessado em 13 de novembro de 2015.
}

Revista Em Debate (UFSC), Florianópolis, volume 13, p. 75-95, 2015. ISSNe 1980-3532 
abordagem sociológica da política, que percebe os processos de tomada de decisão e relações de poder não em si mesmos, mas que emana de fatores sociais que podem ser tomados como objeto da sociologia.

No âmbito da Ciência Política, tal perspectiva estaria próxima das vertentes definida por Hall e Taylor (2003) como "neo-institucionalismos sociológico", que pode ser pensado de acordo com a perspectiva weberiana que tende a valorizar a organização burocrática e racional da política em termos próximos ao de uma empresa moderna. Contudo, considerando ainda, os elementos culturais e históricos que compõem a vida social dos grupos de onde emergem tais estruturas e organizações do poder. Enfim, o documento propõe a discussão de conceitos como: Estado, soberania, sistemas de poder, regimes políticos e democracia, enfatizando a necessidade de levantar questões como as relações entre público e privado e a dinâmica entre centralização e descentralizaçãodo poder - pontos presentes no contexto social brasileiro. Como competência e habilidade associada a essa perspectiva de educação política, tem-se a de contextualização sociocultural que significa a capacidade de:

Construir a identidade social e política, de modo a viabilizar o exercício da
cidadania plena, no contexto do Estado de Direito, atuando para que haja,
efetivamente, uma reciprocidade de direitos e deveres entre o poder público e
o cidadão e também entre os diferentes grupos. (BRASIL, 1999, p.43)

De forma mais aprimorada, a citação nos remete ao objetivo de exercício da cidadania (Lei № 9.394 de 20 de dezembro de 1996), trazendo consigo, no entanto, um contexto mais amplo constituído por mais elementos da Ciência Política e Sociologia. A partir desse momento é possível inferir que esse avanço dos conteúdos de política dentro da sociologia e, consequentemente, aproximação entre as áreas não pode ser dissociada do próprio processo de implementação da Sociologia no Ensino Médiocitado anteriormente. Tal aproximação possibilitou maior visibilidade de temas políticos em aspectos comorelações cotidianas, instituições, relação estado - sociedade, que são consagrados no domínio da sociologia. Nesse sentido, entende-se quea percepção política de fenômenos sociais implica valorizar uma perspectiva interdisciplinar, que enriquece a maneira como discentes observam os fenômenos da sociedade, e valoriza a necessidade de se pensar a inserção do ensino de Ciência Política. Trata-se, assim, de observar o social como político e o político como social.

Retomando o início do texto até chegar a ideia de que as relações sociais também se reproduzem e materializam-se nos produtos coletivos como documentos e 
outros relatórios, é possível pensar todo um campo composto por grupos e atores como a SBS, professores, educadores e políticos, cujas ações na forma de pareceres, análises e projetos se materializou na implementação de uma disciplina que trazia as características sociais presentes em todo esse processo. Em outras palavras, é possível refletir sobre uma implementação de conceitos políticos segundo uma lógica de mobilização orientada para a reivindicação da Sociologia, o que explicaria, em partes, o espaço diminuto, percebido por Magalhães (2012), dado aos conceitos políticos nos documentos oficiais resultantes de todo esse processo.

Em lógica semelhante, podemos problematizar a iniciativa, no ano de 2010, de implementação da Ciência Política como disciplina obrigatória a ser oferecida no Ensino Médio, realizada pelo deputado Ronaldo Caiado (DEM-GO). Segundo uma matéria jornalística veiculada no site da Câmara Legislativa, o projeto de Lei 7746/2010 proposto pelo parlamentar considera que "os alunos do Ensino Médio teriam aulas de conteúdo técnico (e não partidário) sobre a representação política, a história do voto no Brasil e as atribuições dos diferentes cargos políticos e dos três Poderes, entre outros assuntos”. Nessa fonte jornalística oficial, verificamos ainda que o parlamentar afirma que as mudanças realizadas na LDB, no ano de 2008, foram insuficientes e declara: "Essas matérias não abarcam algumas noções imprescindíveis para a compreensão da realidade política brasileira presentes na área de estudo da Ciência Política.

O projeto de lei desenvolvido pelo deputado constitui uma importante fonte que nos oferece outra perspectiva acerca da relação entre Ciência Política e outras disciplinas do Ensino Médio - incluindo, assim, a Sociologia e a Filosofia - como é possível verificar no trecho a seguir:

Em 2008, foi publicada a Lei $n^{\circ} 11.684$, que inclui a Filosofia e a Sociologia como disciplinas obrigatórias em todas as séries do ensino médio. Contudo, 
estas matérias não abarcam algumas noções imprescindíveis para a compreensão da realidade política brasileira presentes na área de estudo da Ciência Política. Portanto, aquela decisão legislativa ficou incompleta, pois faltou a área de conhecimento abrangida pela Ciência Política imprescindível à formação dos jovens no ensino médio. (Brasil, 2010) ${ }^{9}$

Se antes verificamos que ocorria uma aproximação, inclusive teóricometodológica, entre as áreas das ciências sociais, a citação aponta para o início de um processo de diferenciação e autonomia da área de Ciência Política, colocando-a como a disciplina capaz de analisar questões vinculadas "aos direitos e deveres do cidadão, de respeito ao bem comum e à ordem democrática" - valorizadas no artigo 27 da lei $n^{\circ} 9$. 394/1996 que explica que tais questões são tratados pela Filosofia, Geografia, História e Sociologia como problemas pertinentes a vida em sociedade, e não como questões de Ciência Política.

Dessa forma o PL 7746/2010 apresenta um diagnóstico, identifica o problema e aponta a solução, significando um processo de reivindicação de conteúdos e delimitação e imposição de fronteiras para a disciplina almejada no Ensino Médio. Uma maneirade perceber essa relação de diferenciação com mais detalhes é verificando a ilustração 1 que segue e contém o recorte do documento produzido pelo parlamentar, apontando quais seriam essas noções imprescindíveis para a compreensão da realidade política brasileira.

Ilustração 1- recorte do anexo da PL 7746/2010

\footnotetext{
${ }^{9}$ Trecho retirado do projeto de Lei 7746/2010

Revista Em Debate (UFSC), Florianópolis, volume 13, p. 75-95, 2015. ISSNe 1980-3532
} 


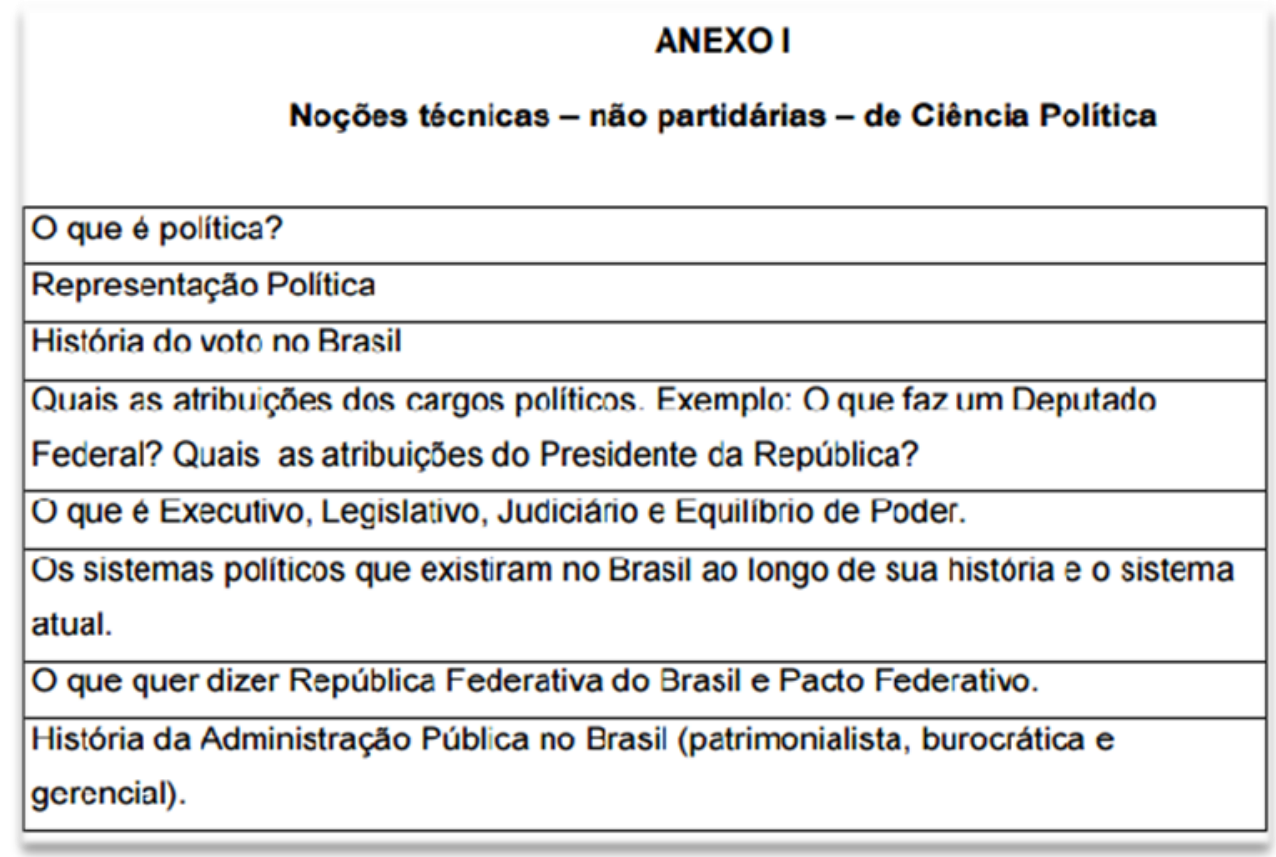

Fonte: BRASIL. Câmara dos Deputados. Projeto de Lei n. 7746/2010. Brasília,DF

Conforme é possível observar na ilustração, as noções e estrutura conceitual apresentam oito pontos que enfatizam a necessidade de uma Ciência Política voltada para a compreensão dos mecanismos operacionais vinculados ao sistema político nacional e instituições políticas oficiais, ou seja, traz uma dimensão mais estrutural, praticamente, oposta àquela verificada anteriormente, na qual a política deveria ser contextualizada com o cotidiano e relações existentes em diferentes grupos nos quais os alunos tivessem contato. Essa perspectiva de Ciência Política, dos direitos e deveres do cidadão e do funcionamento da estrutura política do estado resulta, como observa Schwartzman (1977), da influência de uma vertente tradicional vinculada ao Direito e movimentada por juristas e constitucionalistas que se voltaram para o estudo de uma teoria direcionada para a organização e funcionamento do Estado.

Observou-se, assim, a presença de duas perspectivas: uma jurídica, que tende ao normativismo, já que compreende a política de forma ideal e apartada do processo de construção social da mesma. Um exemplo disso, pode ser pensado quando pegamos o tema dos três poderes no Brasil para serem analisados sob as perspectivas jurídicas e da ciência política, pois enquanto a primeira geralmente é pautada no que os juristas 
chamam de Teoria Geral do $\operatorname{Estado}^{10}$ e na própria constituição de 1988 enfatizando aspectos, no máximo, da filosofia política e aspectos de como deve ser a organização dos três poderes no estado brasileiro, na segunda perspectiva se observa uma série de autores como Scott Mainwaring (2002) Barry Ames (2003)Argelina Maria Cheibub Figueiredo, Fernando Limongi (2001) e outros que se preocupam em demonstram as relações e funcionamentos entre os três poderes, considerando variáveis e fatores que influenciam a dinâmica do sistema político brasileiro.Já no âmbito da antropologia política (KUSCHNIR,2007), outras variáveis como a vida social, família e religião são utilizadas para compreender como a política opera com valores da sociedade, apontando também uma perspectiva que não se orienta por uma percepção de política normativa e de como deveria ser, mas de como essa se manifesta de acordo com condicionantes específicos de cada contexto social e cultural.

Dessa forma a diferença entre as abordagens que priorizam aspectos normativos, institucionais e do cotidiano social, além de apontarem diferentes possibilidades de inserção dos conteúdos de Ciência Política no Ensino Médio e de perfis discentes e docentes- mais investigativos ou normativos, representam também diferentes formas de abordagem, que alimentam um debate e uma reflexão sobre as perspectivas teóricometodológicas da disciplina de maneira mais ampla.

Continuando com a busca dos elementos que estruturam as percepções e produção dos documentos, é possível notar uma diferença entre os próprios atores sociais envolvidos, pois, se na primeira possibilidade de inserção dos conteúdos ocorreu a atuação de atores sociais de diversos setores, como sindicatos de classe, associações nacionais educadores e outros; a segunda tentativa, via projeto de lei, foi sustentada no esforço do deputado Ronaldo Caiado(DEM-GO), que é médico ortopedista, formado na Escola de Medicina e Cirurgia do Rio de Janeiro, produtor rural e presidente da União Democrática Ruralista de 1986 a 1989.

Essas diferentes inserções no debate em torno da inserção da Ciência Política no Ensino Médio, as distintas formações, propostas e interesses sinalizam, entre outras coisas, a característica heterônoma no espaço de debate em torno da questão da Ciência Política como disciplina. Trata-se, assim, de um campo diversificado, cujo resultado

\footnotetext{
${ }^{10}$ Um exemplo é o livro Manual de Teoria Geral do Estado e Ciência Política de José Geraldo Brito Filomeno (2012).
} 
pode ser observado nos diversos documentos produzidos ao longo desse processo e também nos conteúdos que perduraram na grade do Ensino Médio nas escolas pelo país.

\section{Ciências Humanas e suas Tecnologias: Ensino Médio, Cidadania e Democracia}

Se observarmos as orientações educacionais para Ciências Humanas e suas Tecnologias contidas nos Parâmetros Curriculares Nacionais do Ensino Médio (2000) verificaremos que os conteúdos de Ciência Política, especialmente os vinculados às noções de democracia e de cidadania, serão abordados nas áreas de Sociologia, Filosofia, História e Geografia. Os próprios eixos temáticos sugerem isso, já que é possível observar pontos como "Relações de poder e democracia", "Cidadaniadiferenças e desigualdades" e "Política e Sociedade" nas áreas de Filosofia, História e Sociologia.

Se pensada em relação à LDB de 1996, é possível notar um avanço, já que os conceitos de cidadania e democracia podem, atualmente, ser trabalhados de forma mais detalhada e valendo-se da perspectiva interdisciplinar valorizada pelo PCN. Isso ocorre porque em vez de considerar um conjunto de disciplinas isoladamente e seus conteúdos e perspectivas especificas, os conceitos de cidadania e democracia (mais um conjunto de conceitos e temas) acabam servindo como elementos estruturadores de uma nova proposta de Ensino Médio. Dessa maneira, o referido documento contém a seguinte explicação:

\footnotetext{
Cada disciplina apresenta um conjunto de conceitos estruturadores articulados com conhecimentos, que não são só tópicos disciplinares nem só competências gerais ou habilidades, mas sugestões de sínteses de ambas as intenções formativas. Ao se apresentarem dessa forma, esses conceitos estruturadores do ensino disciplinar e de seu aprendizado não mais se restringem, de fato, ao que tradicionalmente se considera responsabilidade de uma única disciplina, pois incorporam metas educacionais comuns às várias disciplinas da área e às das demais áreas, o que implica modificações em procedimentos e métodos, que já sinalizam na direção de uma nova atitude da escola e do professor (BRASIL, 2000.p.13-14)
}

Essa "nova atitude" sinaliza, assim, um contexto marcado pela interdisciplinaridade, no qual a delimitação das fronteiras disciplinares passa a ser substituída por uma perspectiva flexibilizada em função de conceitos centrais, competências e articulação de saberes, resultando em uma relação pragmática com o 
conhecimento. Tem-se, assim, uma mudança de cenário, pois, se anteriormente o argumento para a criação da disciplina de Ciência Política no Ensino Médio era baseado na falta de condições de outras áreas para tratar do tema cidadania, exigindo assim uma definição clara de assuntos e campos de conhecimento, com a perspectiva das Ciências Humanas e suas Tecnologias o viés interdisciplinar tende a dificultar a valorização da inserção de mais uma área disciplinar no currículo.

Um resultado dessa nova perspectiva pode ser verificada no documento “Orientações para o PCN ensino médio + orientações Educacionais Complementares aos Parâmetros Curriculares Nacionais”. Nele é possível observar que a orientação de trabalho para o conceito de democracia é similar na Filosofia e na História, pois a primeira se dedica a participação dos cidadãos na política desenvolvida nas assembleias e na ágora Grega, enquanto na História, é citada a questão da participação ateniense. Em relação ao contexto de formação do estado moderno, ambas coadunam, a primeira focando nos clássicos Maquiavel, Rousseau, Montesquieu e outros que tratam dos limites do poder e soberania popular, enquanto a segunda se detém ao tema da Revolução Francesa, do regime republicano e como esse ocorreu no Brasil. Nesse debate moderno a Geografia também valoriza uma perspectiva política, quando considera o território enquanto unidade política e lugar das relações de poder.

Sobre o contexto contemporâneo as áreas da Filosofia, da História e da Geografia percebemos que também estas possuem temas transversais como o totalitarismo, que pode ser trabalhado na Filosofia, mas que pode, do mesmo modo, ser problematizado na História com apontamentos relacionados à liberdade, à cidadania, às lutas por direitos e por reconhecimento, que por sua vez vão ao encontro de temas geográficos como nacionalismo, separatismos, blocos econômicos e interesses políticos entre outros.

Na Sociologia, além de ser debatida em temas como mudança social e cidadania, problematizando a relação indivíduo e sociedade na produção do Estado e de normas gerais, é possível visualizar o conceito de cidadania no tema cultura e sociedade quando trata da relação entre consumo, cidadania e alienação. A Sociologia contém também as orientações de um eixo chamado "Política e Sociedade", que é subdividido em quatro partes: a) Política e relações de poder; b) Política e Estado; c) Política e Movimentos sociais; e, d) Política e cidadania, que a grosso modo tratam, respectivamente, das relações de poder e ações políticas no cotidiano, das diferentes formas de Estado 
(enfatizando o estado brasileiro e os regimes políticos), mudanças sociais e, por fim, democracia e direitos do cidadão.

Nesse sentido, é possível perceber que em todas as áreas há uma possibilidade de trabalho com temas e conceitos que remontam à necessidade de aplicação de conhecimentos da Ciência Política. No entanto, cabe frisar que nem sempre os autores consagrados da Ciência Política são considerados em todas as áreas de humanas. Ou seja, trata-se muito mais de explicações históricas, filosóficas e geografias de questões pertinentes à política do que uma real incorporação que valorize a inserção de uma nova área de conhecimento. Assim, cabe destacar uma aproximação maior entre as disciplinas Sociologia e Política quando se trata de valorizar os autores consagrados da Ciência Política, aqueles especializados em temas voltados para a democracia e para a cidadania.

Tal relação entre as áreas não pode ser dissociada do fato do domínio preponderante das graduações de Ciências Sociais na formação de licenciados para atuar no Ensino Médio, ou seja, de todas as disciplinas das Ciências Humanas citadas aqui, as Ciências Sociais, da qual se formam os sociólogos, geralmente possuem suas grades curriculares divididas entre disciplinas de Sociologia, Antropologia e Ciência Política, o que possibilita maior condição dos licenciados em transitar pelas três áreas. Enfim, uma forma prática de proceder com a verificação dessa informação, com a própria proposta do PCN de Ciências Humanas e suas Tecnologias e com a possibilidade de pensar a Ciência Política na sala de aula no Ensino Médio, é por meio da análise de livros didáticos desse período escolar que também tratem de conteúdo dessa área.

Considerando essa relação histórica de implementação das áreas de Sociologia e Ciência Política no Ensino Médio, o grande número de eixos temáticos propostos pelo PCN na disciplina de Sociologia e a própria questão da formação em Ciência Sociais, seguiremos com a análise de um livro didático de Sociologia do Ensino Médio, atentando para a relação conceitual, analítica e de diálogo entre as duas áreas.

\section{Ciência Política e Ciências Sociais: Cidadania e Democracia}

Tomando como referência o livro "Sociologia para o Ensino Médio", de Nelson Dacio Tomazi, publicado em 2010 pela Editora Saraiva, seguiremos adiante buscando 
mapear e compreender a Ciência Política em um campo, mais especifico das Ciências Sociais. Sobre a descrição geral do livro, Nascimento explica que:

\begin{abstract}
O livro didático Sociologia para o Ensino Médio organizado em um volume de 256 páginas. Numa linguagem acessível às condições de aprendizagem dos estudantes do Ensino Médio. O livro possui sete unidades temáticas, cada qual dividida em três ou quatro capítulos. Os temas selecionados são: "Sociedade dos indivíduos", "Trabalho e sociedade", "A estrutura social e as desigualdades", "Poder, política e Estado", "Direito, cidadania e movimentos sociais", "Ideologia e cultura" e "Mudança e transformação social". A história da sociologia em geral e no Brasil é apresentada no capítulo introdutório e no apêndice. Os capítulos são organizados tendo um texto explicativo, intermediados por imagens (fotografias, ilustrações, charges) e tabelas, além de boxes com textos complementares e boxes denominados "Nas palavras do Autor", com excertos e fragmentos de textos dos autores citados no capítulo. O livro traz também textos jornalísticos e gráficos relacionados ao mundo contemporâneo seguidos de atividades, sugestões de filmes e de livros (NASCIMENTO, 2012, p.2).
\end{abstract}

Para a presente análise, detalharemos e analisaremos as unidades: "Poder, política e Estado", "Direito, cidadania e movimentos sociais" já que caracterizam bem o tema que são objeto de análise da Ciência Política. A primeira divide-se com os capítulos: 10 - Como surgiu o estado moderno; 11- Poder e estado; 12- Poder política e estado no Brasil; 13 - A Democracia no Brasil. A segunda unidade é composta pelos capítulos: 14 - Direitos e cidadania, 15 - Os movimentos sociais, 16 - Direitos e Cidadania no Brasil e 17 - Os movimentos sociais no Brasil.

Segundo o autor, o objetivo central da unidade seria romper com um preconceito de perceber a política como algo negativo, associado a favores, conchaves e executada unicamente no âmbito do Estado. Após isso, inicia-se uma narrativa explicando as diferentes formas de Estados (Absolutista, Liberal, Nacionais do Século XX, de bemestar social e Neoliberal), apontando as principais características. Nessa etapa a base da abordagem aponta para o uso de autores como Max Weber, quando demonstra as características do estado moderno; John Maynard Keynes, para explicar um pouco do estado de bem-estar social; e Friedrich Von Hayek e Milton Friedman na explicação do estado Neoliberal. Fechando o capítulo, traz trechos de textos de Octavio Ianni e Karl Mannheim, materiais que possibilitam o debate aprofundado sobre os temas do liberalismo, neoliberalismo, liberdade e democracia. A grosso modo, notamos que a opção teórica do referido capítulo segue uma orientação sociológica, tomando os economistas como nativos e a história como campo empírico de demonstração. Sobre o 
desenvolvimento da narrativa histórica, percebe-se a mesma constatação de Sarandy(2010) quando verifica uma perspectiva de história linear no texto do autor ${ }^{11}$.

O capítulo seguinte, "O poder e o Estado", o autor problematiza o Estado como objeto de estudo sociológico e apresenta as principais teorias sociológicas do deste. Se colocando como um mediador entre o leitor secundarista as abordagens complexas do Ensino Superior, o autor apresenta as diferentes perspectivas de Karl Max, comentando as concepções de Estado presentes nos clássicos da Sociologia, ora como reflexo das relações de classe (Karl Marx), ora como organização de interesses coletivos que concentra e expressa a vida social (Emile Durkheim), bem como, uma organização que se vale de vários mecanismos de dominação, de uma burocracia e monopólio da violência (Max Weber).

No tópico "Democracia, representação e partidos políticos", o autor se vale de um conjunto de filósofos para explicar a relação entre democracia liberal, capitalismo e uma linha de pensamento comum defendida por autores como Benjamin Constant (1787-1874), Immanuel Kant (1724- 1804) e Edmund Burke (1729-1797). Demonstra, por outro lado, a perspectiva de Claude Lefort e a crítica do mesmo ao pensamento liberal no aspecto de exclusão da participação, diminuição de direitos e de princípios democráticos.Adentrando sobre alguns autores consagrados na Ciência Política, segue o texto citando alguns estudiosos como Joseph Schumpeter, Giovanni Sartori, Robert Dahl, Adam Przeworski, Guillermo O’Donnell, importantes nomes da teoria democrática contemporânea que, a grosso modo, tem se dedicado as questões institucionais e de operacionalização da participação política sobre diferentes perspectivas - eleições competitivas, cidadania abrangente, proteção de direitos no estado autoritário e outras. Por fim, traz a contribuição do sociólogo Boaventura de Sousa Santos particularmente no que tange sua observação sobre a legitimidade da democracia representativa e seus efeitos práticos no mundo contemporâneo.

Para demonstrar análises sobre a organização e formas de poder que ultrapassam as esferas do Estado e se manifestam em outros momentos da vida, o livro traz o tópico "A Sociedade disciplinar e a sociedade de controle", cujo título já evidencia a

${ }^{11}$ Trata-se de um estudo realizado sobre o livro Iniciação à Sociologia de Nelson DacioTomazi que foi publicado pela Atual Editora, em São Paulo, no ano de 1999. No texto selecionado, Sarandy(2010) discorre sobre os diferentes tipos de estados e formação do estado moderno, em um texto similar ao analisado aqui. 
importância dada a Michel Foucault no livro "A microfísica do poder" e, também, de outros filósofos como Gilles Deleuze e Theodor Adorno.

De modo geral, os tópicos 12-Poder, Política e Estado no Brasil e 13-A Democracia no Brasil, trazem, primeiramente, uma história política dos diferentes tipos de Estado no Brasil (Monarquia, República velha, República nova, republica dos generais e Estado democrático). Exposta tal contextualização, apresenta uma discussão sobre as regras de participação ao longo da história, atentando para as lutas por direitos civis, políticos e sociais. Explica sobre o descrédito nos partidos, observadas como verdadeiras máquinas de obter voto, e lança, ainda, reflexões sobre a relação entre Estado e sociedade. Para finalizar os tópicos, o autor discorre sobre um conjunto de termos como: privatização, coronelismo, nepotismo, corrupção, despolitização e outros diretamente relacionados aos contextos históricos apresentados. Embora seja utilizado apenas o sociólogo Ruda Ricci, o texto também nos faz pensar em autores como José Murilo de Carvalho e seus estudo sobre cidadania no Brasil; e Vitor Nunes Leal, com seu clássico Coronelismo, Enxada e Voto (2012).

Já a unidade 5- Direitos, Cidadania e Movimentos Sociais apresenta uma abordagem interessante que mescla elementos da Ciência Política, do Direito e Sociologia, e compreende que as mudanças no âmbito do reconhecimento e direitos são resultados de lutas. Nos dois primeiros tópicos (14-Direitos e Cidadania e 15- Os Movimentos Sociais)expõe um histórico de algumas das principais revoluções e documentos resultantes de processos revolucionários, na Inglaterra e na França. Para refletir sobre as questões da igualdade e cidadania lança mão dos filósofos contratualistas (Thomas Hobbes, Jon Locke e Jean-Jacques Rousseau) e depois Karl Marx e Émile Durkheim.

Ao desenvolver o tópico sobre movimentos sociais, valoriza aspectos como: reconhecimento, confronto, parceria e entendimento do movimento social como ação coletiva. Embora o autor ressalte apenasa referência dos estudos de Axel Honneth sobre reconhecimento, cremos também que essa abordagem seja influenciada pela teoria do processo político, ou seja, uma perspectiva que entende o movimento social enquanto fenômeno político. Seguindo o autor, discorre sobre as greves no contexto industrial, novos movimentos sociais (ambientalista e feminista) e as busca por reconhecimento.

Nos dois últimos tópicos (16 - Direitos e Cidadania no Brasil e 17 -Os Movimentos Sociais no Brasil), há uma contextualização dos dois tópicos com a 
situação brasileira. Seguindo declaradamente a linha de José Murilo de Carvalho e T.H. Marshall, o autor traz um histórico dos períodos políticos no país e suas relações com os direitos civis, políticos e sociais, concluindo que no Brasil o que ocorreu de forma diferente da Europa, e que existem várias possibilidades de problematizar a cidadania no país (regulada, formal, substantiva). Em relação aos movimentos sociais, faz uma narrativa interdisciplinar entre história, sociologia e política, sinalizando os direitos e aspectos políticos contidos nas principais revoltas e mobilizações ocorridas desde o período colonial até os dias atuais. Pedagogicamente, toma temas antes trabalhados exclusivamente na História, valorizando as dimensões políticas e sociológicas dos mesmos.

Os temas sobre democracia, cidadania, movimentos sociais são trabalhados à luz de uma narrativa que aponta as interpretações produzidas pela filosofia política dos contratualistas e filósofos liberais, pela sociologia política dos clássicos e contemporâneos e também, por um conjunto de autores mais facilmente identificados com a história política e Ciência Política como é o caso de José Murilo de Carvalho, Joseph Schumpeter, Wanderley Guilherme dos Santos, Giovanni Sartori, Robert Dahl, Adam Przeworski e Guillermo O’Donnell.

Enfim, após o estudo detalhado do conteúdo, pode-se dizer que o livro didático reflete a situação da Ciência Política no Brasil, ou seja, marcada por uma pluralidade de abordagens e métodos. Para autores como Frojaz (1997) eSchwartzman(1977), oprocesso de institucionalização da Ciência Política no Brasil esteve marcada pela existência de diferentes grupos de intelectuais e pela ausência de uma coesão quanto as formas de abordagens e métodos. Schwartzman(1977) explica que parte da Ciência Política é alimentada por um conjunto de conceitos filosóficos, no entanto existiram outras vertentes mais próximas da Sociologia e da Economia. A grosso modo, aponta que existem pelo menos três agendas de pesquisa na área, voltadas para as pesquisas sobre o funcionamento e constituição do estado, outras focadas no sistema governamental e, por fim, na pesquisa que se detém sobre as decisões políticas e seus impactos. Agendas que lançam mão de métodos das pesquisas quantitativos, históricas, sociológicas, organizacionais etc.

É importante, também, considerar a própria formação do autor do livro didático que é licenciado em Ciências Sociais pela Universidade Federal do Paraná, mestre em História pela Universidade Estadual Paulista de Assis, e doutor em História pela 
Universidade Federal do Paraná. Tal formação possibilita tanto uma compreensão de Ciência Política marcada por uma pluralidade de métodos e abordagens, quanto uma percepção histórico-Sociológica mais elaborada dos fenômenos políticos. Sobre isso Sarandi(2010) explica que de forma geral, o conteúdo desse livro segue a mesma perspectiva orientadora de programas de graduação em Ciências Sociais.

Tal formação e orientação, evidencia o argumento de Frojaz(1997) quando explica que na relação entre Ciência Política e Ciências Sociais, a primeira seria a irmã caçula da segunda e que o processo de institucionalização dela ocorreu durante a década de 1960 atrelada à implementação de um sistema de pós-graduação e montagem de programas e órgãos de desenvolvimento científico vinculado às políticas de planejamento econômico e às agências de fomento à pesquisa. Nesse sentido, o caminho de institucionalização da Ciência Política possuiu maiores investimentos na pósgraduação, caracterizando um caminho distinto da Sociologia, cuja formação universitária existe desde a década de 1930 na Universidade de São Paulo.

\section{Conclusões preliminares}

Após essa breve tentativa de sistematização e compreensão da inserção da Ciência Política no Ensino Médio, é possível concluir que o processo de reconhecimento dessa disciplina não pode ser compreendido fora do campo, composto por diferentes interesses e posições, no qual estabelece relação com outras áreas de conhecimento e com diversos atores no decorrer dos últimos anos.

A observação desse trabalho coletivo possibilitou compreender alguns aspectos importantes do processo de institucionalização dessa área no Ensino Médio. Primeiramente, em um contexto no qual notamos a presença de conteúdos de Ciência Política trabalhados pelas outras áreas das ciências humanas(Sociologia, Geografia, Filosofia, História etc..). A observação de diferentes atores, fontes documentais apontam que os conhecimentos de Ciência Política eram vinculados à Filosofia, ao Direito e especialmente à Sociologia, cuja história de inserção no Ensino Médio está diretamente vinculada à incorporação de temas e aos conceitos políticos no referido nível de ensino. 
Outro caminho foi com o reforço do aspecto disciplinar das áreas de conhecimentos (delimitação de fronteiras disciplinares) e justificou a inserção da Ciência Política como disciplina na grade do Ensino Médio, tomando como referência uma perspectiva tradicional vinculada a uma concepção de política herdada do Direito.

No contexto de valorização das Ciências Humanas e suas Tecnologias, a inserção de uma disciplina de Ciência Política no Ensino Médio parece ter se diluído com os novos ares da interdisciplinaridade propagados nas novas orientações vinculadas aos Parâmetros Curriculares Nacionais. A análise dessas orientações demonstra um argumento de falta de necessidade de implementação de uma disciplina de Ciência Política, uma vez que os conceitos de cidadania, democracia e estado estão presentes em vários eixos temáticos propostos para as disciplinas de História, Geografia, Filosofia e Sociologia.

Sendo produzida no âmbito das Ciências Sociais, a formação em Sociologia ocorre permeada por uma capacidade de interdisciplinaridade, já que é desenvolvida ao lado das disciplinas de Antropologia e Ciência Política. É possível verificar a materialidade dessa formação no livro didático aqui analisado, já que os conteúdos e currículo do autor sinalizam a perspectiva das Ciências Sociais, que por sua vez representa um estágio do próprio processo de institucionalização da Ciência Política, que diferentemente da Sociologia, que teve início no Ensino Superior na década de 1930, consolidou-se a partir da década de 1960 na pós-graduação.

Enfim, a partir dos itinerários e diálogos descritos aqui, é possível pensar o reconhecimento da Ciência Política no Ensino Médio pela busca de produção de um espaço autônomo de atuação no qual as justificativas, regras e orientações sigam os parâmetros da própria área. Não se trata de algo no âmbito do Ensino Médio, mas de algo mais amplo, como apontam os estudos de Frojaz (1997). Nesse sentido, pensar o Ensino Médio da Ciência Política, significa refletir sobre o processo de formação de licenciados em Ciência Política, ou seja, problematizar, debater, pesquisar -no âmbito das pós-graduações- sobre a reprodução e consolidação dessa área em outros níveis de ensino. Por sua vez, debater a necessidade de licenciados em Ciência Política é consequentemente a busca de um aprimoramento da educação básica e alimentação do debate sobre os conceitos de cidadania, de democracia, de estados e de movimentos sociais. 


\section{Referências}

AMES Barry. Os entraves da democracia no Brasil/Barry Ames. Tradução de Vera Pereira- Rio de Janeiro: Editora FGV, 2003.

BOURDIEU, Pierre. O Poder Simbólico.Bertand Brasil:Rio de Janeiro, 2004. Coisas ditas. São Paulo: Brasiliense, 1990.

BRASIL/MEC. Lei de Diretrizes e Bases 9394/96, Brasília, DISTRITO FEDERAL, 1996. Disponível em: http://www.planalto.gov.br/ccivil 03/leis/L9394.htm. Acessado em 20 de julho de 2016.

BRASIL/MEC. Lei nº11. 684/2008. D.O.U. DE 03/06/2008, P. 1 Disponível em: http://www.planalto.gov.br/ccivil_03/_Ato2007-2010/2008/Lei/L11684.htm

BRASIL. Câmara dos Deputados. Projeto de Lei n. 7746 de 2010. Brasília, DF: Câmara dos Deputados, 8. fev. 2010. Disponível em:

http://www.camara.gov.br/proposicoesWeb/prop_mostrarintegra?codteor=793061\&file $\underline{\text { name }=P L+7746 / 2010}$

BRASIL. Parâmetros curriculares nacionais: ensino médio (parte IV: ciências humanas e suas tecnologias). Brasília: Ministério da Educação/Secretaria de Educação Média e Tecnológica, 1999.

FIGUEIREDO, Argelina Cheibub. Executivo e Legislativo na nova ordem constitucional / Argelina Cheibub Figueiredo e Fernando Limongi. - $2^{\mathrm{a}}$ ed. - Rio de Janeiro: Editora FGV, 2001.

FILOMENO, José Geraldo Brito. Manual de Teoria Geral do Estado e Ciência Política. Rio de Janeiro, Forense, 2012.

FORJAZ, Maria Cecília Spina. A emergência da Ciência Política acadêmica no Brasil: aspectos institucionais. Rev. bras. Ci. Soc. [online]. 1997, vol.12, n.35 .

HALL, Peter A. and TAYLOR, Rosemary C. R. As três versões do neoinstitucionalismo. Lua Nova [online]. 2003, n.58, pp. 193-223.

MARX, Karl. O 18 de Brumário de Louis Bonaparte. Lisboa Moscovo, Edições Avante, 1982.

MICELI, Sérgio "Condicionantes do Desenvolvimento das Ciências Sociais no Brasil: 1930-1964", Revista Brasileira de Ciências Sociais, vol. 2, n 5, outubro 1987.

LEAL, Victor Nunes. Coronelismo, enxada e voto: o município e o regime representativo no Brasil. $7^{a}$ edição. São Paulo: Companhia das Letras, 2012. 
MAINWARING, Scott. Presidencialismo y democracia en América latina / Scott Mainwaring y Matthew Soberg Shugart.- I a ed.- Buenos Aires : Paidós, 2002.

NASCIMENTO, Lidiane Rocha do. ANÁLISE DA CATEGORIA TRABALHO EM LIVROS DIDÁTICOS DE SOCIOLOGIA. Trabalho apresentado no $3^{\circ}$ ENSOC Encontro Estadual de Ensino de Sociologia . 28, 29 e 30 de setembro de 2012 Faculdade de Educação UFRJ. Disponível em: www.labes.fe.ufrj.br/Eventos/3ENSOC/. Acesso em 20 de julho de 2016.

KUSCHNIR, Karina. Antropologia e política. Rev. bras. Ci. Soc. [online], vol.22, n.64, p. 163-167, 2007.

SARANDY, Flávio Marcos Silva. A sociologia volta à escola: um estudo dos manuais de sociologia para o ensino médio no Brasil. Dissertação de mestrado/Pós-Graduação em Sociologia e Antropologia/Universidade Federal do Rio de Janeiro (UFRJ). Rio de Janeiro, 2004.

SCHWARTZMAN, Simon. Avaliação e perspectivas da área de ciência política. Comité Assessor em Ciências Sociais do Conselho Nacional de Desenvolvimento Científico e Tecnológico (CNPq). Relator, Simon, abril de 1977. Disponível em: http://www.schwartzman.org.br/simon/cpolitica.htm\#_1_4. Acesso em 20 de maio de 2016.

TOMAZI, Nelson D. Sociologia para o Ensino Médio. $1^{\circ}$ edição. São Paulo: Saraiva, 2010. 